\title{
Lipotropes enhance the anti-proliferative effect of chemotherapeutic drugs in MCF-7 human breast cancer cells
}

\author{
KYONGSHIN CHO, LAWRENCE MABASA, MARK W. WALTERS and CHUNG S. PARK \\ Department of Animal Sciences, North Dakota State University, Fargo, ND 58102, USA
}

Received December 27, 2012; Accepted February 15, 2013

DOI: $10.3892 /$ or.2013.2404

\begin{abstract}
Increasing evidence indicates that dietary intake of methyl nutrients is associated with the risk of breast cancer. Lipotropes are methyl group-containing essential nutrients (methionine, choline, folate and vitamin $\mathrm{B}_{12}$ ) which play key roles in one-carbon metabolism; however, little is known about the implications of lipotropes in possible tumor-suppressive effects with chemotherapeutic drugs for breast cancer. In the present study, we investigated the in vitro effects of lipotropes on cell growth and apoptosis of MCF-7 human breast cancer cells. Cells were cultured and treated with lipotropes, and cell proliferation, apoptosis and gene expression were determined. Also, the possible synergistic effects of lipotropes with anticancer drugs, the histone deacetylase inhibitor suberoylanilide hydroxamic acid (SAHA) and doxorubicin (DOX), were examined. Lipotropes significantly reduced the growth of MCF-7 cells and increased apoptosis as well as upregulation of caspase-3 and tumor protein 53 (p53) enzyme activities. Gene transcription, as measured by quantitative real-time PCR, revealed a significant increase of p53 mRNA in MCF-7 cells treated with lipotropes, but there were no differences in two drug-resistant related genes. Moreover, lipotropes showed significant additive effects with SAHA and DOX on cell growth inhibition. These results suggest that lipotropes induce apoptosis, inhibit cell growth, and display anti-proliferative
\end{abstract}

Correspondence to: Professor Chung S. Park, Department of Animal Sciences, North Dakota State University, 1300 Albrecht Avenue, Fargo, ND 58102, USA

E-mail: c.park@ndsu.edu

Abbreviations: ABCC1, ATP-binding cassette sub-family C member 1; ABCG2, ATP-binding cassette sub-family G member 2; ACTB, $\beta$-actin; CpG, cytosine-phosphate-guanine dinucleotide; DOX, doxorubicin; ELISA, enzyme-linked immunosorbent assay; ER, estrogen receptor; ESR1, estrogen receptor 1 gene; HDAC, histone deacetylase; MDM, murine double minute oncogene; MeCP2, methyl CpG binding protein 2; p53, tumor protein 53; RT-PCR, reverse transcription-polymerase chain reaction; SAHA, suberoylanilide hydroxamic acid

Key words: lipotrope, breast cancer, MCF-7, p53, suberoylanilide hydroxamic acid, doxorubicin, histone deacetylase effects with SAHA and DOX in MCF-7 cells. Owing to the tumor-suppressive effects observed, lipotropes in combination with chemotherapeutic drugs may be tested further in animal models as potential therapeutic agents for reducing breast cancer risk.

\section{Introduction}

We recently described in vivo effects of high-dose lipotropes that reduce mammary tumor growth of female rat offspring by suppressing histone deacetylase 1 (HDAC1) gene expression (1). In an attempt to further expand our knowledge on the effects of high-dose lipotropes, we conducted a series of in vitro experiments using MCF-7 human breast cancer cells in which we combined lipotropes with chemotherapeutic drugs such as the HDAC inhibitor suberoylanilide hydroxamic acid (SAHA) and the anticancer drug doxorubicin (DOX).

Nutritional studies as well as epidemiological studies have shown that dietary manipulation of methyl donors and cofactors (either deficiency or supplementation) can lead to permanent alterations in patterns of gene expression (2). Mammalian methyl metabolism is dependent on dietary nutrients which influence DNA and histone methylation (3). Previous studies revealed that reduced dietary intake or low tissue/plasma levels of methyl nutrients are associated with higher risk for developing cancer, while increased methyl nutrient intake reduces the risk of neural tube defects and the incidence of low birth weight $(4,5)$.

Lipotropes are methyl group-containing essential nutrients (methionine, choline, folate and vitamin $\mathrm{B}_{12}$ ) which can affect genomic DNA methylation, a process correlated with controlling the expression of genes involved in cell growth, apoptosis, and metabolism (6-8). Lipotropes play key roles in one-carbon metabolism, a process that maintains the imprinting status of genes and provides methyl groups for all biological methylation pathways (6-8). Methionine and choline are major methyl donors, while folate and vitamin $\mathrm{B}_{12}$ are critical cofactors for methyl metabolism (7). Methyl donors and cofactors are also involved in the synthesis of nucleotides and phospholipids as well as amino acid metabolism and signal transduction $(3,8)$.

Apoptosis is critical for the pathogenesis of cancer and its regulation is often impaired in cancer cells (9). Caspase-3 is a critical regulator involved in the execution phase of apoptosis and some cancer cells evade apoptosis by suppressing caspase-3 (10). The p53 tumor suppressor gene plays a key 
role in inhibiting cancer cell growth and murine double minute oncogene 2 (MDM2) binds specifically to the $\mathrm{p} 53$ protein and negatively regulates its transcriptional activity and stability through multiple mechanisms in cancer cells $(11,12)$. The interruption of p53 activity by MDM2 is one of the main mechanisms by which cancer cells evade apoptosis (12).

Increasing the susceptibility of tumor cells to apoptosis is one of the main strategies of cancer treatment (9). HDAC inhibitors are emerging chemotherapeutic drugs and have been characterized as potential inducers of growth arrest and apoptosis of cancer cells in vitro and in vivo (13). Drug resistance of cancer cells to a variety of chemotherapeutic agents is one of the major obstacles for cancer treatment (14). Defects in apoptosis signaling contribute to the development of drug resistance in cancer chemotherapy (15). Apoptosis plays an essential role in drug resistance and modulating apoptosis in tumor cells is a principal target in breast cancer treatment (15).

Although there is a growing body of literature investigating the intake of individual nutrients and breast cancer risk, less is known about the interplay among these methyl nutrients and their implications for breast cancer risk reduction. Herein, we investigated the relationship between apoptosis and the synergistic effects of lipotropes with anticancer drugs in MCF-7 human breast cancer cells.

\section{Materials and methods}

Cell line and cell culture. The estrogen receptor (ER) positive MCF-7 (HTB-22, adenocarcinoma) human breast cancer cell line was purchased from the American Type Culture Collection (ATCC, Manassas, VA, USA). The cells were grown in Dulbecco's modified Eagle's medium (Gibco Invitrogen, Carlsbad, CA, USA) supplemented with $10 \%(\mathrm{v} / \mathrm{v})$ heat-inactivated fetal bovine serum (Gibco Invitrogen) and $1 \%(\mathrm{v} / \mathrm{v})$ antibiotic-antimycotic (Gibco Invitrogen) solution as recommended by the supplier. Cells were maintained as monolayer cultures in $25-$ and $75-\mathrm{cm}^{2}$ tissue culture flasks (BD Biosciences, Franklin Lakes, NJ, USA) at $37^{\circ} \mathrm{C}$ in a $5 \%$ $\mathrm{CO}_{2}$-humidified atmosphere during experimentation. Cells were passaged using $0.5 \%$ trypsin-EDTA (Gibco Invitrogen) at $80-90 \%$ confluence. The lipotrope stock solutions were prepared by dissolving L-methionine, choline chloride, and folic acid (Table I) (Sigma-Aldrich, St. Louis, MO, USA) in culture media and filtered aseptically through $0.45 \mu \mathrm{m}$ pore size cellulose acetate membrane filters (Nalgene, Rochester, NY, USA). The stock solutions were pre-warmed and vigorously stirred before adding to cell cultures. The appropriate or optimal dose of lipotropes was determined from dose response studies $(0,5,10$ and 20 times).

Cell proliferation assay. Colorimetric MTS [3-(4,5-dimethylthiazol-2-yl)-5-(3-carboxymethoxyphenyl)-2-(4-sulfophenyl)2H-tetrazolium] assay (CellTiter $96^{\circledR}$ AQueous One Solution Reagent; Promega, Madison, WI, USA) was used to measure cell proliferation. Briefly, cells were seeded in 96-well flatbottomed tissue culture plates $\left(5 \times 10^{3}\right.$ cells/well in $\left.100 \mu \mathrm{l}\right)$, and incubated with various concentrations of lipotropes for a duration of $0,24,48,72$ or $96 \mathrm{~h}$ in cultures. Following incubation, $10 \mu \mathrm{l}$ of MTS solution was added and cells were incubated at $37^{\circ} \mathrm{C}$ for a further $1-4 \mathrm{~h}$. The degree of cell proliferation was
Table I. Amount of lipotropes in culture medium.

\begin{tabular}{lcc}
\hline & \multicolumn{2}{c}{ DMEM } \\
\cline { 2 - 3 } Ingredients (mg/l) & Control (basal) & Lipotropes (20x) \\
\hline L-Methionine & 30.0 & 600.0 \\
Choline chloride & 4.0 & 80.0 \\
Folic acid & 4.0 & 80.0 \\
Vitamin $\mathrm{B}_{12}$ & 0.0 & 0.0
\end{tabular}

The amounts of lipotropes indicate in basal and lipotrope-fortified media. DMEM, Dulbecco's modified Eagle's medium.

evaluated numerically by measuring the absorbance at $490 \mathrm{~nm}$ with a SpectraMax Microplate Reader (Molecular Devices, Sunnyvale, CA, USA). The cell proliferation was calculated and expressed based on the following formula: \{[treated cell absorbance - initial (seeding) cell absorbance]/initial (seeding) cell absorbance\} x 100 .

Caspase- 3 assay. The caspase- 3 activity was measured by a colorimetric assay with the CaspACE assay system (Promega). Briefly, cells were cultured in 6-well flat-bottomed tissue culture plates $\left(5 \times 10^{4}\right.$ cells $\left./ \mathrm{ml}\right)$ and treated with lipotropes (20 times) for 96 h. Cells were harvested and washed twice with ice-cold PBS and then lysed in lysis buffer (Promega). The protein concentration was quantified using a NanoDrop 2000c (Thermo Fisher Scientific, Waltham, MA, USA). Cell lysates (25 $\mu \mathrm{g} / \mathrm{sample})$ were incubated with colorimetric substrate, N-acetyl-Asp-GluVal-Asp-amino-p-nitroanilide (Ac-DEVD-pNA). Following overnight incubation at $4^{\circ} \mathrm{C}$, the release of p-nitroaniline from Ac-DEVD-pNA was measured at $405 \mathrm{~nm}$ using a SpectraMax Microplate Reader (Molecular Devices).

p53 assay. The p53 activity was determined using an enzyme immunometric assay kit (TiterZyme ELISA Kit, Assay Designs, Ann Arbor, MI, USA). Briefly, cells were cultured in 6-well flat-bottomed tissue culture plates $\left(5 \times 10^{4}\right.$ cells $\left./ \mathrm{ml}\right)$ and treated with lipotropes (20 times) for $96 \mathrm{~h}$. Cells were harvested and washed twice with ice-cold PBS and then resuspended in lysis buffer (Sigma-Aldrich). The protein concentration was quantified using a NanoDrop 2000c (Thermo Fisher Scientific). The supernatants (100 $\mu \mathrm{g} / \mathrm{sample})$ were incubated on a plate preimmobilized with $\mathrm{p} 53$ polyclonal antibody and then reacted with the labeled antibody. The absorbance was measured at $450 \mathrm{~nm}$ using a SpectraMax Microplate Reader.

Flow cytometric analysis. Apoptosis was determined by doublestaining with fluorescein isothiocyanate (FITC)-conjugated Annexin V and propidium iodide (PI) (Sigma-Aldrich) as previously described (16). Briefly, cells were cultured in 12-well flat-bottomed tissue culture plates $\left(5 \times 10^{4}\right.$ cells $\left./ \mathrm{ml}\right)$ and treated with lipotropes (20 times) for $96 \mathrm{~h}$. After harvesting, cells were washed with PBS and resuspended in assay buffer (SigmaAldrich). Cells were stained with FITC-conjugated Annexin V and PI, and then analyzed using Accuri C6 cytometer and CFlow software (Accuri Cytometers, Ann Arbor, MI, USA). 

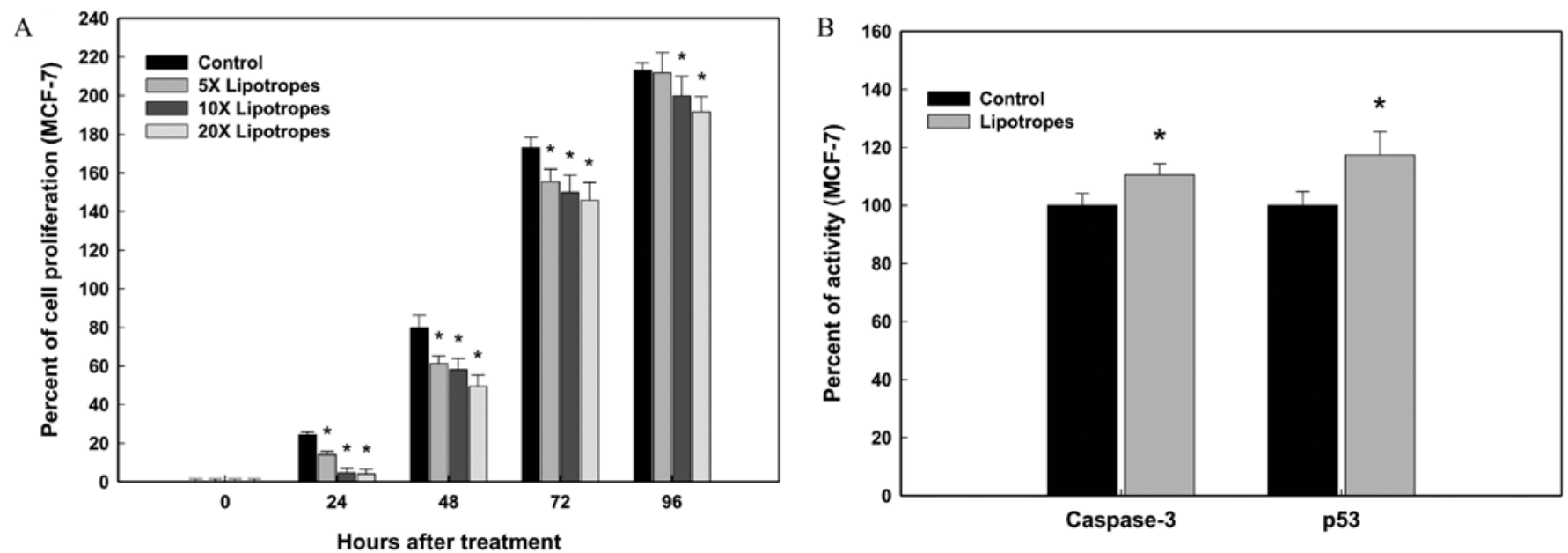

Figure 1. Effects of lipotropes on the cell growth and activities of caspase-3 and p53 in MCF-7 cells. (A) Cells were treated with lipotropes for 0, 24, 48, 72, or $96 \mathrm{~h}$ and cell proliferation was determined by MTS assay $(\mathrm{n}=8)$. (B) Cells were treated with 20 times of lipotropes for $96 \mathrm{~h}$, and caspase-3 and p53 activities were measured (caspase-3, $n=5 ; \mathrm{p} 53, \mathrm{n}=4$ ). Data are expressed as the means $\pm \mathrm{SD}$. Asterisk indicates a statistically significant difference between two groups of cells $(\mathrm{P}<0.05)$.

Quantitative real-time PCR. MCF-7 cells treated with lipotropes (20 times) for $96 \mathrm{~h}$ were harvested and placed in RNAlater (Ambion, Austin, TX, USA) prior to freezing, and then disrupted into small pieces. RNA was purified by the standard method. Briefly, cells were homogenized in TRI Reagent (Molecular Research Center, Cincinnati, OH, USA) and total RNA was isolated using 1-bromo-3-chloropropane phase separation reagent (Molecular Research Center). RNA was precipitated by isopropanol and washed with $75 \%$ ethanol and then the RNA pellet was dried and resuspended in RNase-free water. The RNA concentration was quantified using a NanoDrop 2000c (Thermo Fisher Scientific). A total of $1 \mu \mathrm{g}$ RNA of each sample was reverse-transcribed to cDNA using the QuantiTect Reverse Transcription kit (Qiagen, Valencia, CA, USA) and a 2720 Thermal Cycler (Applied Biosystems, Foster City, CA, USA) at $42^{\circ} \mathrm{C}$ for $15 \mathrm{~min}$, and $95^{\circ} \mathrm{C}$ for $3 \mathrm{~min}$, in accordance with the manufacturer's recommendations. Real-time RT-PCR was performed with SYBR-Green PCR Master Mix (Applied Biosystems) using a 7500 Fast Real-Time PCR system (Applied Biosystems) with QuantiTect Primers (Qiagen, product reference is in brackets); tumor protein $\mathrm{p} 53$ ( $p 53$, QT00060235), murine double minute oncogene (MDM2, QT00056378), estrogen receptor 1 (ESRI, QT00044492), ATP-binding cassette sub-family C member 1 (ABCCl, QT00061159), and ATP-binding cassette sub-family G member 2 (ABCG2, QT00073206). The relative amounts of gene expression were standardized and calculated by the expression of house-keeping control gene, $\beta$-actin (ACTB, QT01680476) as an internal standard, using the $2^{-\Delta \Delta \mathrm{Ct}}$ method.

Cell proliferation assay with anticancer drugs. MCF-7 cells were seeded in 96-well flat-bottomed tissue culture plates $\left(5 \times 10^{4}\right.$ cells $\left./ \mathrm{ml}\right)$ and cultured simultaneously with media containing dimethyl sulfoxide (DMSO, Sigma-Aldrich) vehicle alone or $250 \mathrm{nM} \mathrm{SAHA}$ (Enzo Life Sciences, Farmingdale, NY, USA) and/or lipotropes (20 times). DOX is a well known anticancer drug with broad spectrum antitumor efficacy, including human breast cancer (17). MCF-7/DOX (DOX-resistant MCF-7) cells were seeded in 96-well flat-bottomed tissue culture plates $\left(5 \times 10^{4}\right.$ cells $\left./ \mathrm{ml}\right)$ and cultured simultaneously with media containing $100 \mathrm{nM}$ of DOX (Sigma-Aldrich) and/ or lipotropes (20 times). The cell proliferation was measured by the MTS assay.

Statistical analysis. For the comparison of two groups with similar variance, a paired t-test was used. Means of several groups were compared with one-way analysis of variance (ANOVA) followed by Tukey's test. Statistical data analyses were performed using Minitab Release 14.1 (Minitab Inc., State College, PA, USA). $\mathrm{P}<0.05$ was considered to indicate statistically significant differences.

\section{Results}

Lipotropes significantly reduce MCF-7 cancer cell growth. The cell proliferation of MCF-7 cells was examined over a wide range of doses and times for dose- and time-dependent studies. Lipotropes (20 times) lowered the cell density of MCF-7 cells at 24, 48, 76 and $96 \mathrm{~h}$ following treatment (Fig. 1A). At a 10 times concentration and $96 \mathrm{~h}$, lipotropes showed a mild growth inhibitory effect on MCF-7 cells. As shown in Fig. 1A, lipotropes resulted in a significant growth reduction of MCF-7 cells in dose- and time-dependent manners, which was detectable during early and late phases of cell growth. In MCF-7 cells, lipotropes (20 times) caused $83.6 \%$ growth reduction at $24 \mathrm{~h}$ after treatment, compared to the control. The dose of lipotropes (20 times) for maximum cancer cell growth inhibition was used for subsequent experiments.

Lipotropes significantly increase caspase- 3 and $p 53$ activities in MCF-7 cells. In order to determine if lipotropes inhibit the growth of MCF-7 cells by inducing cell death, caspase- 3 and p53 activities were measured using colorimetric assays at $96 \mathrm{~h}$ after treatment. In MCF-7 cells, lipotropes (20 times) increased 


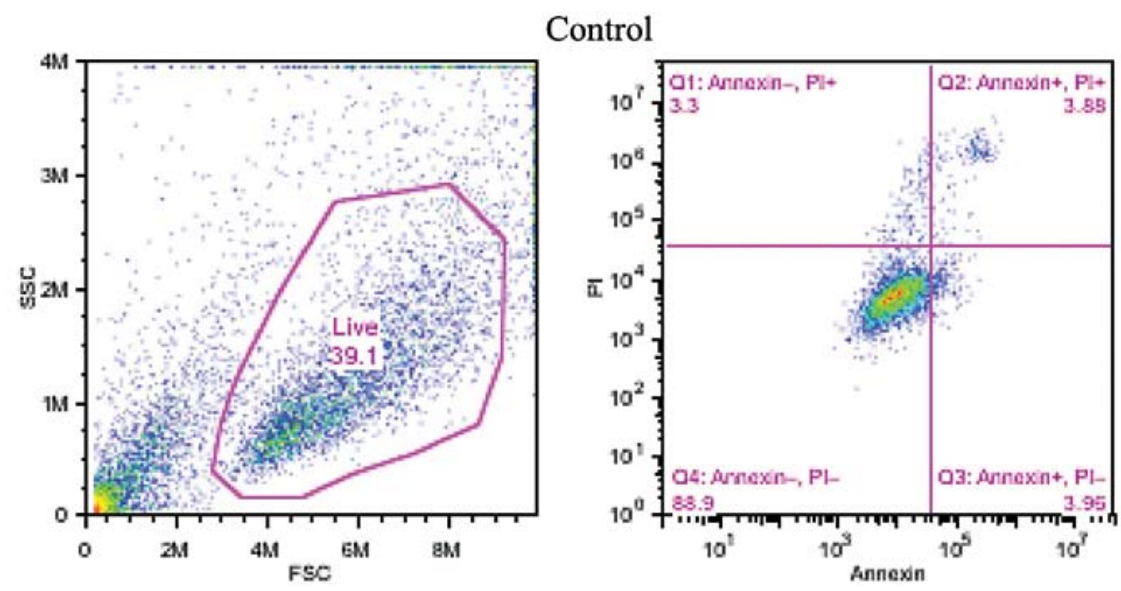

Lipotropes
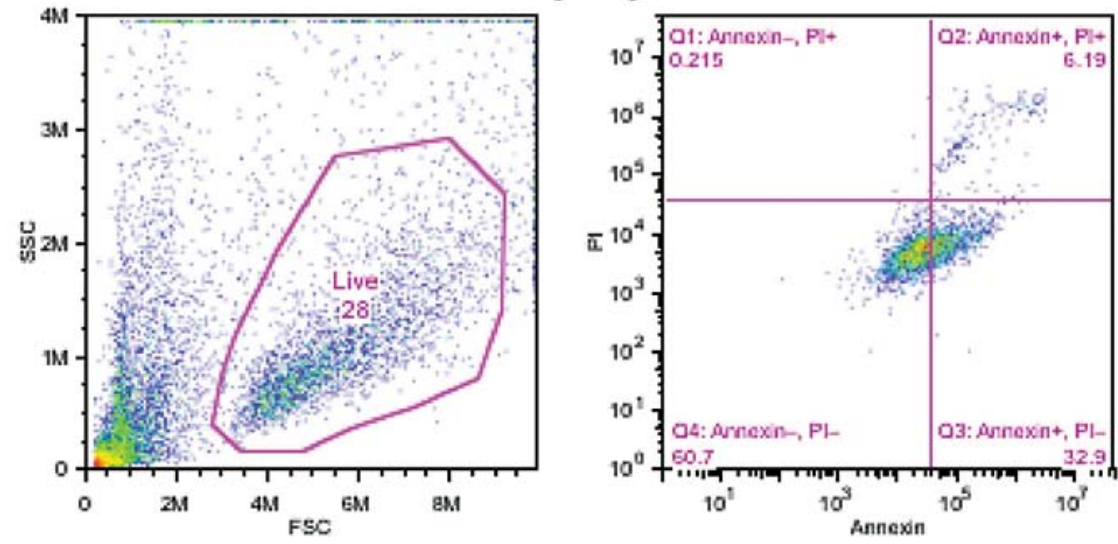

Figure 2. Apoptosis of MCF-7 cells treated with 20 times lipotropes for 96 h. Harvested cells were stained with Annexin V-FITC (FL1, x-axis) and PI (FL2, $\mathrm{y}$-axis). Cells were measured by forward scattering (FSC, size) and side scattering (SSC, granularity) of flow cytometry. Results represent viable cells (lower-left quadrant), necrotic cells (upper-left quadrant), early apoptotic cells (lower-right quadrant) and late apoptotic cells (upper-right quadrant).

both caspase- 3 and 553 activity. At $96 \mathrm{~h}$ after treatment, lipotropes increased the caspase- 3 activity in MCF-7 cells (10.5\%; Fig. 1B). Consistent results were obtained from the p53 assay. At 96 h, p53 activity was significantly upregulated in MCF-7 cells (14.8\%; Fig. 1B). These results suggest that lipotropes induce apoptosis in MCF-7 cells, at least partially by modulating caspase-3 and p53 activities.

Lipotropes induce apoptosis in MCF-7 cells. Apoptosis was measured using a flow cytometric assay with Annexin V and PI at $96 \mathrm{~h}$ after treatment. As shown in Fig. 2, lipotropes (20 times) increased apoptosis (upper- and lower-right quadrants), $+31.3 \%$ in MCF-7 cells (7.8 vs. $39.1 \%$ ). Moreover, lipotropes showed a decreased percentage of live cells, -11.1 in MCF-7 cells (39.1 vs. 28.0\%) as shown in Fig. 2 (left panels). These results indicate that lipotropes induce apoptotic cell death in the early (lower-right quadrant) and late (upper-right quadrant) apoptosis stage of MCF-7 cancer cells.

Expression of genes associated with apoptosis, cancer and drug resistance in MCF-7 cells. The mRNA levels of apoptosis- and cancer-related genes in MCF-7 cells were analyzed by quantitative real-time PCR. As shown in Table II, lipotropes did not affect the expression of MDM2, ESR 1, ABCC1 and $A B C G 2$ genes in MCF-7 cells treated with 20 times lipotropes for $96 \mathrm{~h}$. However, lipotropes significantly increased $p 53$ gene expression (41.1\%) in MCF-7 cells. The p53 data supports the
Table II. Expression of apoptosis- and cancer-related genes in MCF-7 cells.

\begin{tabular}{lcccc}
\hline \multirow{2}{*}{$\begin{array}{l}\text { Gene } \\
\text { symbol }\end{array}$} & \multicolumn{2}{c}{ Treatment } & & Fold- \\
\cline { 2 - 3 } & Control & Lipotropes & difference & P-value \\
\hline$p 53^{\mathrm{a}}$ & $0.88 \pm 0.35$ & $1.24 \pm 0.15$ & 1.41 & $0.03^{\mathrm{d}}$ \\
$M D M 2^{\mathrm{a}}$ & $1.12 \pm 0.15$ & $0.94 \pm 0.29$ & 0.84 & 0.11 \\
$E S R 1^{\mathrm{b}}$ & $1.07 \pm 0.10$ & $1.00 \pm 0.39$ & 0.93 & 0.72 \\
$A B C C 1^{\mathrm{c}}$ & $1.16 \pm 0.16$ & $0.93 \pm 0.36$ & 0.80 & 0.14 \\
$A B C G 2^{\mathrm{c}}$ & $1.22 \pm 0.48$ & $1.00 \pm 0.43$ & 0.82 & 0.34 \\
\hline
\end{tabular}

Data represent mRNA levels $(n=5)$ and are expressed as means \pm SD The relative amounts of gene expression were standardized and calculated by the expression of the house-keeping gene, $\beta$-actin. ${ }^{\text {TTumor }}$ protein 53 (p53) and murine double minute 2 oncogene (MDM2) were used as apoptosis markers. ${ }^{\mathrm{b} E s t r o g e n}$ receptor 1 (ESRI) was used as a breast cancer marker. ${ }^{\mathrm{c}} \mathrm{ATP}$-binding cassette sub-family $\mathrm{C}$ member 1 $(A B C C 1)$, and ATP-binding cassette sub-family G member 2 (ABCG2) were used as drug resistance markers. ${ }^{\mathrm{d}}$ Statistically significant difference between two groups of cells $(\mathrm{P}<0.05)$.

results of the caspase-3, p53, and flow cytometric assays and also indicates that lipotropes reduce cancer cell growth by inducing apoptosis. 
A

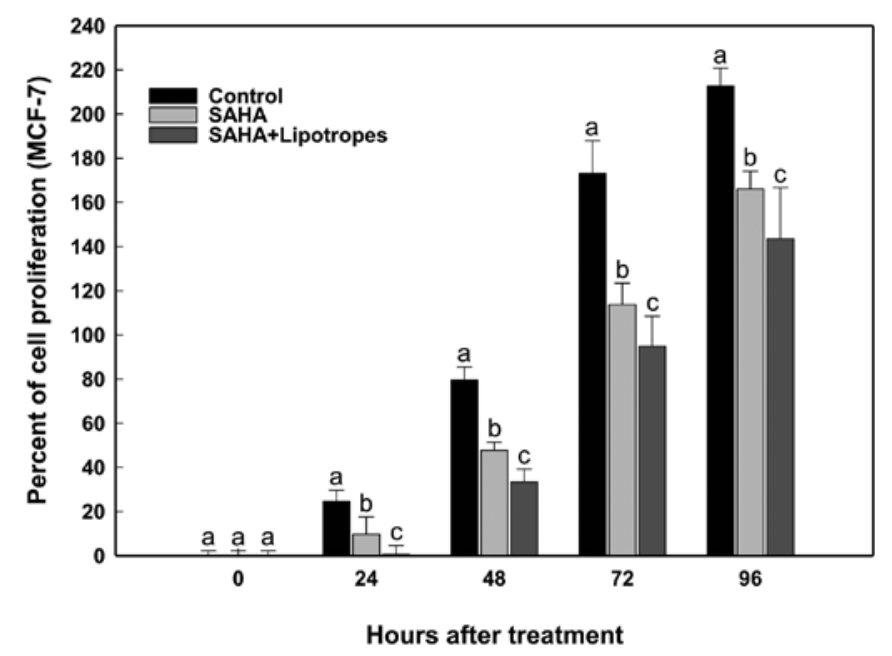

B

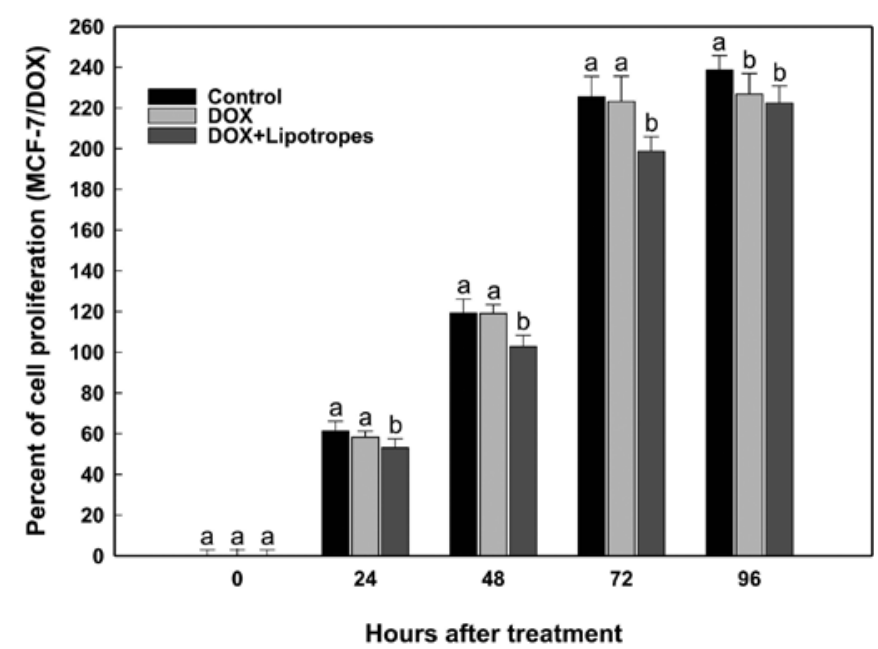

Figure 3. Effects of lipotropes on MCF-7 cell growth in combination with histone deacetylase (HDAC) inhibitor suberoylanilide hydroxamic acid (SAHA) and anticancer drug doxorubicin (DOX). (A) MCF-7 cells were exposed to $250 \mathrm{nM}$ of SAHA and/or lipotropes (20 times) for $0,24,48,72$, or $96 \mathrm{~h}(\mathrm{n}=8)$. (B) MCF-7/DOX (DOX-resistant MCF-7) cells were exposed to $100 \mathrm{nM}$ of DOX and/or lipotropes (20 times) for $0,24,48,72$, or $96 \mathrm{~h}(\mathrm{n}=8)$. Cell proliferation was measured by MTS assay. Data are expressed as the means \pm SD. Different letters indicate a statistically significant difference from each other $(\mathrm{P}<0.05)$.

Lipotropes show additive effects with HDAC inhibitor SAHA and anticancer drug DOX in the growth inhibition of MCF-7 cells. Although no significant differences in the expression of drug resistance genes ( $A B C C 1$ and $A B C G 2)$ were found, the possible synergistic or additive effect of lipotropes in combination with chemotherapeutic agents was investigated. The HDAC inhibitor SAHA and anticancer drug DOX were assessed in combination with lipotropes (20 times). As shown in Fig. 3, lipotropes showed significant additive effect with SAHA in MCF-7 cells (Fig. 3A) and inhibitory effect with DOX in MCF-7/DOX cells (Fig. 3B). This indicates that the observed in vitro effects of lipotropes might reflect a response towards apoptosis rather than modifying chemotherapeutic drug effects.

\section{Discussion}

Breast cancer is the most common malignancy in women in the United States, accounting for approximately 40,000 deaths each year (18). Nearly one out of every eight women develops breast cancer during her lifetime (19). The incidence of breast cancer is associated with lifestyle, and nutrition is one of the most important factors influencing the risk of breast cancer (18). In January 1998, the US Food and Drug Administration mandated the folate fortification of all enriched cereal-grain products in the United States (20). This policy was intended to ensure sufficient folate intake among women of childbearing age in order to decrease the risk of neural tube defects in their babies (20). Some case-control studies have demonstrated that increased intake of methyl nutrients may reduce the risk of breast cancer, while low intake of methyl nutrients is associated with an elevated risk of breast cancer $(7,21)$. In mammals, methyl metabolism is dependent on dietary methyl nutrients which influence DNA and histone methylation of genes (8).

Lipotropes significantly inhibited MCF-7 human breast cancer cell growth (Fig. 1A). Lipotropes also showed significantly increased caspase-3 and p53 levels in MCF-7 cells (Fig. 1B). These findings show that in MCF-7 cells treated with lipotropes, increased activities of caspase- 3 and p53 correlate with MCF-7 cell growth inhibition, possibly due to apoptosis. Similarly, the flow cytometric result showed increased apoptosis, confirmed by Annexin V and PI (Fig. 2). Apoptosis has been accepted as a fundamental process in the elimination of defective or unwanted cells in multicellular organisms (22), and caspases are the important components in the initiation and execution of apoptosis, with caspase-3 being a key mediator of apoptosis (10). In order to suppress cancer, the p53 tumor suppressor protein induces or represses a multitude of genes encoding proteins involved in key processes, including cell cycle control, DNA repair, senescence, and apoptosis $(23,24)$. Regulating the transcriptional activity of p53 in cancer cells is one of the main strategies to increase the susceptibility of cancer cells to apoptosis in cancer treatment (9).

Estrogen receptor (ER) plays a role in breast cancer development and the abundance of this receptor tends to increase in breast cancer (25). The development of drug resistance to a variety of chemotherapeutic agents is one of the major obstacles for cancer treatment (14). Drug resistance often results from the overexpression of members of the ATP-binding cassette $(\mathrm{ABC})$ transporter family, such as ATP-binding cassette sub-family $\mathrm{C}$ member 1 (ABCC1) and ATP-binding cassette sub-family G member 2 (ABCG2) (26-28). Lipotropes significantly increased $\mathrm{p} 53$ gene expression, but the expression of $M D M 2, E S R 1, A B C C 1$ and $A B C G 2$ genes showed similar levels between two groups (Table II). Collectively, these results suggest that lipotropes reduce MCF-7 cell growth in relation to p53-dependent apoptosis through transcriptional and translational control.

Lipotropes enhanced the tumor-suppressive effects of the histone deacetylase (HDAC) inhibitor suberoylanilide hydroxamic acid (SAHA) and the anticancer drug doxorubicin (DOX) on MCF-7 cell growth (Fig. 3). HDAC inhibitors are emerging anticancer drugs and SAHA is a potent HDAC inhibitor, causing growth arrest and apoptosis in several types of cancer (13). DNA methylation correlates with epigenetic 
regulation of oncogenes and tumor suppressor genes (29). Methyl CpG binding protein 2 (MeCP2) selectively recognizes methylated $\mathrm{CpG}$ dinucleotides and forms a complex with HDAC, thereby suppressing gene transcription leading to chromatin remodeling (30). Some studies have shown that, compared to normal cells, $M e C P 2$ and HDAC1 gene expression is elevated in cancer cells (31).

The present study demonstrated that lipotropes induce apoptosis and show anti-proliferative effects in combination with SAHA and DOX in MCF-7 cells. The findings of the present study provide insight for understanding dietary intervention of methyl nutrients in cancer cell growth and apoptosis, and yield useful information in designing the in vivo and in vitro experiments to reduce breast cancer risk.

\section{Acknowledgements}

The authors thank Dr Elena V. Batrakova (University of Nebraska) for kindly providing the MCF-7/DOX cell line and Dr Raushan K. Singh for technical assistance. The present study was partially supported by the US DODCDMRP/BCRP (grant W81XWH-09-1-0610).

\section{References}

1. Cho K, Mabasa L, Bae S, Walters MW and Park CS: Maternal high methyl diet suppresses mammary carcinogenesis in female rat offspring. Carcinogenesis 33: 1106-1112, 2012.

2. Zeisel SH: Epigenetic mechanisms for nutrition determinants of later health outcomes. Am J Clin Nutr 89: 1488S-1493S, 2009.

3. Van den Veyver IB: Genetic effects of methylation diets. Annu Rev Nutr 22: 255-282, 2002.

4. Zhang SM, Willett WC, Selhub J, Hunter DJ, Giovannucci EL, Holmes MD, Colditz GA and Hankinson SE: Plasma folate, vitamin $B_{6}$, vitamin $B_{12}$, homocysteine, and risk of breast cancer. J Natl Cancer Inst 95: 373-380, 2003.

5. Beilby J, Ingram D, Hähnel R and Rossi E: Reduced breast cancer risk with increasing serum folate in a case-control study of the C677T genotype of the methylenetetrahydrofolate reductase gene. Eur J Cancer 40: 1250-1254, 2004.

6. Park CS, Cho K, Bae DR, Joo NE, Kim HH, Mabasa L and Fowler AW: Methyl-donor nutrients inhibit breast cancer cell growth. In Vitro Cell Dev Biol Anim 44: 268-272, 2008.

7. Newberne PM: Lipotropic factors and oncogenesis. Adv Exp Med Biol 206: 223-251, 1986.

8. Mason JB: Biomarkers of nutrient exposure and status in onecarbon (methyl) metabolism. J Nutr 133: 941S-947S, 2003.

9. Call JA, Eckhardt SG and Camidge DR: Targeted manipulation of apoptosis in cancer treatment. Lancet Oncol 9: 1002-1011, 2008.

10. Riedl SJ and Shi Y: Molecular mechanisms of caspase regulation during apoptosis. Nat Rev Mol Cell Biol 5: 897-907, 2004.

11. Kussie PH, Gorina S, Marechal V, Elenbaas B, Moreau J, Levine AJ and Pavletich NP: Structure of the MDM2 oncoprotein bound to the p53 tumor suppressor transactivation domain. Science 274: 948-953, 1996.
12. Eischen CM and Lozano G: p53 and MDM2: antagonists or partners in crime? Cancer Cell 15: 161-162, 2009.

13. Marks PA, Richon VM, Miller T and Kelly WK: Histone deacetylase inhibitors. Adv Cancer Res 91: 137-168, 2004.

14. Linn SC, Pinedo HM, van Ark-Otte J, van der Valk P, Hoekman K, Honkoop AH, Vermorken JB and Giaccone G: Expression of drug resistance proteins in breast cancer, in relation to chemotherapy. Int J Cancer 71: 787-795, 1997.

15. Eliopoulos AG, Kerr DJ, Herod J, Hodgkins L, Krajewski S, Reed JC and Young LS: The control of apoptosis and drug resistance in ovarian cancer: influence of p53 and Bcl-2. Oncogene 11: 1217-1228, 1995.

16. Cho K, Mabasa L, Fowler AW, Walsh DM and Park CS: Canola oil inhibits breast cancer cell growth in cultures and in vivo and acts synergistically with chemotherapeutic drugs. Lipids 45 : 777-784, 2010.

17. Singal PK and Iliskovic N: Doxorubicin-induced cardiomyopathy. N Engl J Med 13: 900-905, 1998.

18. Jemal A, Siegel R, Xu J and Ward E: Cancer statistics, 2010. CA Cancer J Clin 60: 277-300, 2010.

19. Feuer EJ, Wun LM, Boring CC, Flanders WD, Timmel MJ and Tong T: The lifetime risk of developing breast cancer. J Natl Cancer Inst 85: 892-897, 1993.

20. Honein MA, Paulozzi LJ, Mathews TJ, Erickson JD and Wong LY: Impact of folic acid fortification of the US food supply on the occurrence of neural tube defects. JAMA 285: 2981-2986, 2001.

21. Das PM and Singal R: DNA methylation and cancer. J Clin Oncol 22: 4632-4642, 2004.

22. Khan N, Adhami VM and Mukhtar H: Apoptosis by dietary agents for prevention and treatment of cancer. Biochem Pharmacol 76: 1333-1339, 2008.

23. Oren M: Decision making by p53: life, death and cancer. Cell Death Differ 10: 431-442, 2003.

24. Meek DW: Tumour suppression by p53: a role for the DNA damage response? Nat Rev Cancer 9: 714-723, 2009.

25. Lapidus RG, Nass SJ and Davidson NE: The loss of estrogen and progesterone receptor gene expression in human breast cancer. J Mammary Gland Biol Neoplasia 3: 85-94, 1998.

26. Pohl A, Devaux PF and Herrmann A: Function of prokaryotic and eukaryotic $\mathrm{ABC}$ proteins in lipid transport. Biochim Biophys Acta 1733: 29-52, 2005.

27. Kaminski WE, Piehler A and Wenzel JJ: ABC A-subfamily transporters: structure, function and disease. Biochim Biophys Acta 1762: 510-524, 2006.

28. Park S, Shimizu C, Shimoyama T, Takeda M, Ando M, Kohno T, Katsumata N, Kang Y, Nishio K and Fujiwara Y: Gene expression profiling of ATP-binding cassette (ABC) transporters as a predictor of the pathologic response to neoadjuvant chemotherapy in breast cancer patients. Breast Cancer Res Treat 99: 9-17, 2006.

29. Razin A: CpG methylation, chromatin structure and gene silencing-a three-way connection. EMBO J 17: 4905-4908, 1998.

30. Fuks F, Hurd PJ, Wolf D, Nan X, Bird AP and Kouzarides T: The methyl-CpG-binding protein MeCP2 links DNA methylation to histone methylation. J Biol Chem 278: 4035-4040, 2003.

31. Müller HM, Fiegl H, Goebel G, Hubalek MM, Widschwendter A, Müller-Holzner E, Marth C and Widschwendter M: MeCP2 and MBD2 expression in human neoplastic and non-neoplastic breast tissue and its association with oestrogen receptor status. Br J Cancer 89: 1934-1939, 2003. 